\title{
Improvement in lacrimal and salivary secretions after alkali therapy in Sjøgren's syndrome with renal tubular acidosis
}

\author{
C. T. FLYNN, T. W. NEGUS, J. MCHARDY, AND D. J. RAINFORD \\ From Princess Mary's Royal Air Force Hospital, Aylesbury
}

\begin{abstract}
Flynn, C. T., Negus, T. W., McHardy, J., and Rainford, D. J. (1976). Annals of the Rheumatic Diseases, 35, 381-384. Improvement in lacrimal and salivary secretions after alkali therapy in Sjegren's syndrome with renal tubular acidosis. A patient with Sjøgren's syndrome developed renal tubular acidosis which led to systemic acidosis and potassium depletion. Treatment with Shohl's solution and potassium supplements was followed by subjective improvement in tear flow, salivary flow, and by disappearance of bronchitic symptoms. Detailed objective assessments were then made during the next year, twice on treatment and twice without. These confirmed the subjective impression of improvement.
\end{abstract}

Renal tubular acidosis has been well described in association with Sjøgren's syndrome, both in its overt (Shearn and Tu, 1965; Talal, 1966; Morris and Fudenberg, 1967) and its latent form (Shearn and Tu, 1968). Renal tubular acidosis is characterized by a systemic hyperchloraemic acidosis with an associated inability to excrete an appropriately acid urine. The impairment of acid excretion is disproportionate to any reduction in the glomerular filtration rate. It is generally considered that no treatment will improve the secretions of the salivary or lacrimal glands in Sjøgren's syndrome (Hughes and Whaley, 1972), although some slight improvement with cyclophosphamide has been reported (Anderson and others, 1972).

We report the case of a woman with Sjøgren's syndrome and associated overt renal tubular acidosis in whom treatment of the renal tubular acidosis resulted in gross clinical improvement of the xerostomia and xerophthalmia both subjectively and objectively. The detailed investigation of this woman is described and the possible mechanisms relating to her clinical improvement are discussed.

\section{Case report}

A caucasian female, now aged 45 years, first noticed dryness of both eyes early in 1970 . She was seen at the Royal Infirmary, Dundee, in June 1970, when a diagnosis of keratoconjunctivitis sicca was made, and treatment with artificial tears (methyl cellulose in Ringer's solution) was prescribed. In 1971 she developed a dry mouth and suffered dental caries complicated by osteomyelitis of the jaw. Antibiotic treatment was followed by a severe allergic reaction.

She was admitted to this hospital in May 1972. In addition to dry eyes and mouth she complained of a dry unproductive cough, weight loss, and thirst for the past 6 months. On examination the mouth was dry and the eyes showed filiform punctate keratitis. There were scattered rhonchi in both lungs and the forced vital capacity (FVC) measured 3.0 1 against a predicted FVC of 3.71 . The forced expiratory volume in one second $\left(F_{1} V_{1}\right)$ was $60 \%$ of FVC. Chest $x$-ray was normal. The cardiovascular system was normal and the blood pressure $110 / 70 \mathrm{mmHg}$. Abdominal examination was normal and there was no skin disease, lymphadenopathy, or arthritis. The central nervous system was normal except for extremely brisk tendon reflexes, which were symmetrical, and bilateral ankle clonus. There was a moderate iron deficiency anaemia confirmed by bone marrow biopsy, the initial haemoglobin estimation being $10.6 \mathrm{~g} / \mathrm{dl}$. Total white cell count was only $3.0 \times 10^{9} / 1\left(3000 / \mathrm{mm}^{3}\right)$ with a normal differential.

Intravenous urogram was normal. Creatinine clearance was normal, with a serum creatinine of $88.4 \mu \mathrm{mol} / \mathrm{l}$ $(1.0 \mathrm{mg} / 100 \mathrm{ml})$. The maximal specific gravity of a morning urine sample was 1014 . Water deprivation tests were avoided. Plasma $\mathrm{pH}$ was $7 \cdot 33$, plasma bicarbonate $14 \mathrm{mmol} / \mathrm{l}(14 \mathrm{Eq} / \mathrm{l})$, and a simultaneous urine $\mathrm{pH} 6 \cdot 75$. These findings were diagnostic of renal tubular acidosis and an ammonium chloride acid load test (Wrong and Davies, 1959) was considered unnecessary. The findings were confirmed by repeated testing. Plasma potassium 


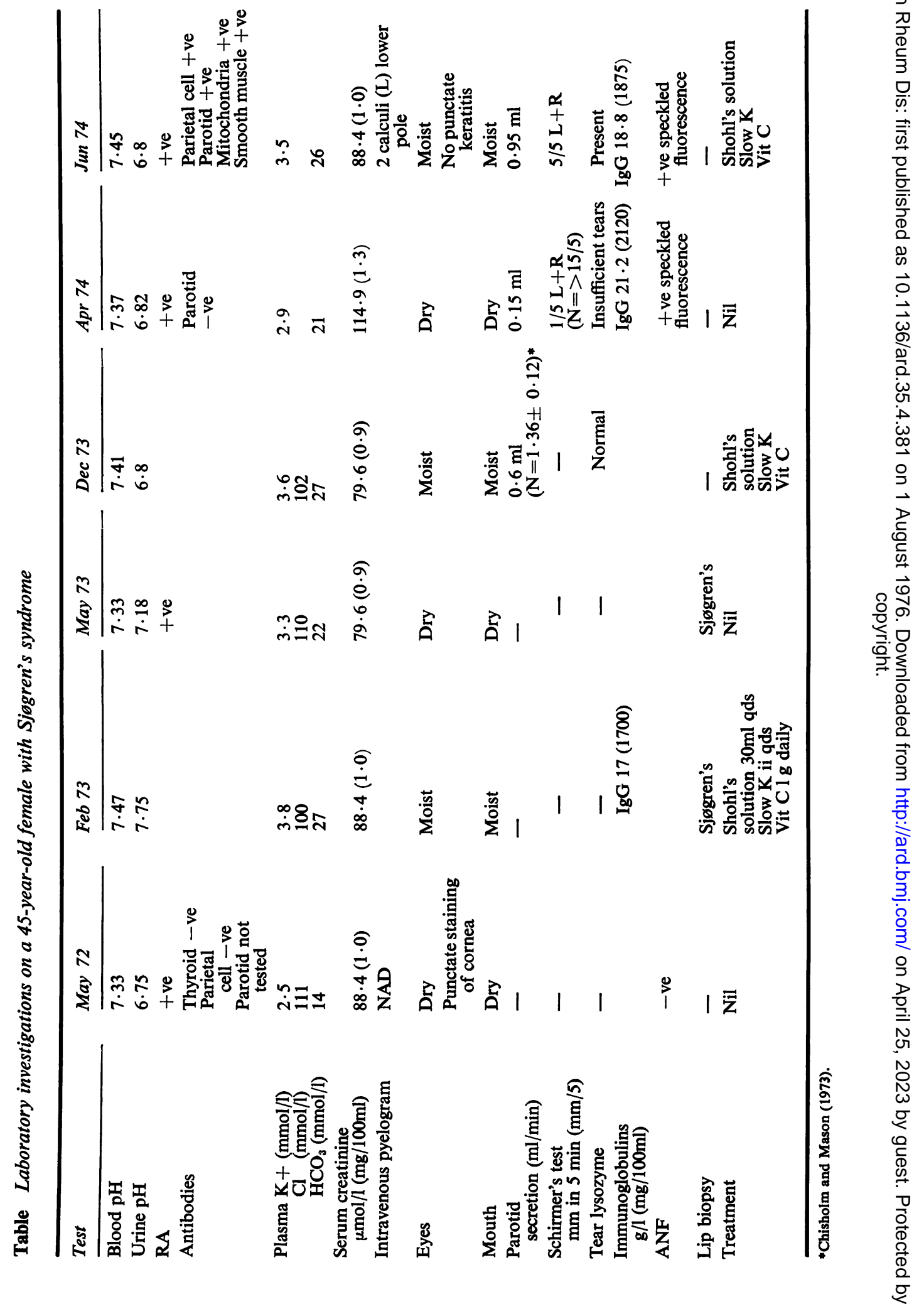


was consistently low despite the acidosis (minimum value $2.5 \mathrm{mmol} / 1(2.5 \mathrm{mEq} / \mathrm{l}))$ indicating a concomitant severe potassium depletion. The acidosis was thought to be the cause of both the hypereflexia and potassium depletion and treatment was started with Shohl's solution (sodium citrate $10 \mathrm{~g}$, citric acid $6 \mathrm{~g}$, made up to $100 \mathrm{ml}$ with distilled water) and Slow $\mathrm{K}$ tablets (see Table). After this she gained weight, the cough disappeared, she reported that her mouth was moist, and artificial tears were needed only two or three times a day instead of every hour.

In February 1973, after some 8 months' treatment, she was reassessed. Both eyes were grossly normal and the buccal mucosa moist. Gum biopsy showed lymphocytic infiltration consistent with Sjøgren's syndrome. She was seen for the first time by a dental surgeon at this hospital whose opinion was, "clinically there seems to be a relatively normal salivary secretion'. Shohl's solution and potassium supplements were stopped and she was reassessed in May 1973. She complained bitterly of dry eyes and mouth, which was confirmed on examination, and the cough had returned. Treatment with Shohl's solution and potassium was restarted. Her weight had again fallen. Quantitative estimate of salivary flow on treatment was made in December 1973, at which time she was clinically normal. Treatment was continued until February 1974. She was then asked to stop treatment and report to hospital if her symptoms became intolerable. Final assessment without therapy was carried out in April 1974 at which time the salivary flow had sharply decreased.

Treatment was again started with marked clinical improvement. However, in June 1974 she developed abdominal pain and a normal appendix was removed at another hospital. On recovery she was admitted to this hospital where two calculi were found in the lower pole of the left kidney. The history suggested ureteric colic rather than appendicitis. Because of this development it was thought that it would be unethical to stop treatment with Shohl's solution or potassium to assess the effect of each on her apparent improvement on treatment.

Many other tests had been performed during the management of her condition. Diagnosis of Sjøgren's syndrome was supported by the following. The antinuclear factor was consistently positive, as was the rheumatoid factor (RA screening). Antibodies to parietal cells, parotid gland cells, mitochondria, and smooth muscle were present in the blood. The results of the investigations are set out in the Table. Salivary flow was measured using a modified Carlsen-Crittenden cup (Mason and others, 1967), and tear secretion by Schirmer's test (Schirmer, 1903).

\section{Discussion}

Sjøgren's syndrome (Sjøgren, 1933) consists of a triad of xerostomia, keratoconjunctivitis sicca, and a connective tissue disorder. The presence of two of the three components is generally sufficient for the diagnosis. There is a female preponderance and a high incidence of allergic reactions to antibiotics (Bloch and others, 1965). Antibodies to a large number of tissues may be found (Bloch and Bunim,
1963). Renal tubular acidosis occurs in a proportion of patients (Shearn and Tu, 1965; Talal, 1966; Morris and Fudenberg, 1967) and may be latent (Shearn and Tu, 1968). There is no doubt that the patient amply fulfils the criteria for the diagnosis of Sjøgren's syndrome.

Renal tubular acidosis may also occur in Wilson's disease, hyperthyroidism, pyelonephritis, multiple myeloma, galactosaemia, Lowe's syndrome, cystinosis, potassium deficiency, heavy metal poisoning, from the effects of nephrotoxic drugs (Huth, Maycock, and Kerr, 1959; Milne, 1963), and after cadaver kidney transplantation (Massry and others, 1967). All these conditions can be confidently excluded in this patient except for the potassium deficiency. However, potassium deficiency is itself a complication of renal tubular acidosis, and may contribute to a vicious cycle, as potassium depleted subjects challenged by acid loads excrete a urine of higher $\mathrm{pH}$ than normal subjects (Wrong and Davies, 1959).

In the cases of latent renal tubular acidosis described by Shearn and Tu (1968) all the patients had normal serum potassium levels, suggesting that potassium deficiency is unlikely to be the primary cause in Sjøgren's syndrome. The aetiology of renal tubular acidosis is unknown, although it occurs in hyperglobulinaemic states (Cohen and Way, 1962; Morris and Fudenberg, 1967). Although patients with Sjøgren's syndrome may have hyperglobulinaemia, the patient in this case did not, which argues against this being a primary cause. It is also known that patients with Sjøgren's syndrome may develop lymphoid tumours (Talal and Bunim, 1964) and that the onset of such may be accompanied by a fall in globulin levels. However, there is no clinical evidence that the patient is developing a lymphoid tumour and she has been under observation for $2 \frac{1}{2}$ years from the discovery of renal tubular acidosis. The prompt response to Shohl's solution suggests that the renal tubular defect was of a distal tubular type (Pitts, 1974) and not due to proximal tubular bicarbonate wasting.

It is difficult to explain the improvement in lacrimal and salivary secretion after treatment. It has been generally considered up to now that no treatment actually improves these secretions (Hughes and Whaley, 1972). Reliance has been placed on artificial tears and mouth washes. Corticosteroids do not seem of value (Bloch and others, 1965), although some improvement with cyclophosphamide has been reported (Anderson and others, 1972). Pathologically, the characteristic change in the salivary and lacrimal glands is a diffuse lymphocytic infiltration which may lead to destruction and loss of secretory tissue. It is unlikely that correction of this patient's metabolic abnormalities affected gland morphology or had any influence on the basic disease process. It is 
much more likely that the subjective and objective improvement was related to an improvement in residual function.

The initial history of weight loss which returned to normal after starting therapy indicates that sodium depletion was the most important contributory factor. Acidosis and potassium depletion were also involved, but it is difficult to make a case for either of these as singular factors in isolation. Despite the inability to evaluate fully the subjective and objective improvement in salivary and lacrimal gland secretion, we regard this unexpected phenomenon as an important observation.

It is suggested that those who deal with large numbers of cases of Sjøgren's syndrome might seek a diagnosis of renal tubular acidosis and disturbances of metabolism more assiduously, as correction of these factors might, as in our case, improve the well being of their patients.

We thank the Director General of Medical Services (RAF) for permission to publish.

\section{References}

Anderson, L. G., Cummings, N. A., Asofsky, R., Hilton, M. B., TARPley, T. M., JR., Tomasi, T. B., JR., Wolf, R. O., Schall, G. L., TALAL, N. (1972) Amer. J.Med., 53, 456 (Salivary gland immunoglobulin and rheumatoid factor synthesis in Sjøgren's syndrome. Natural history and response to treatment)

Bloch, K. J., AND Bunim, J. J. (1963) J. chron. Dis., 16, 915 (Sjøgren's syndrome and its relation to connective tissue disease)

—, Buchanan, W. W., Wohl, M. J., And Bunim, J. J. (1965) Medicine, 44, 187 (Sjøgren's syndrome. A clinical, pathological and serological study of sixty-two cases)

Chisholm, D. M., and Mason, D. K. (1973) Brit. dent. J., 135, 393 (Salivary gland function in Sjøgren's syndrome)

Cohen, A., AND WAY, B. J. (1962) Aust. Ann. Med., 11, 189 (The association of renal tubular acidosis with hyperglobulinaemic purpura)

Hughes, G. R. V., AND Whaley, K. (1972) Brit. med. J., 4, 533 (Sjøgren's syndrome)

Huth, E. J., MAYCOCK, R. L., AND KerR, R. M. (1959) Amer.J. Med., 26, 818 (Hyperthyroidism associated with renal tubular acidosis. Discussion of possible relationship)

Mason, D. K., Harden, R. McG., Boyle, J. A., Jasani, M. K., Williamson, J., and Buchanan, W. W. (1967) Ann. rheum. Dis., 26, 311 (Salivary flow rates and iodine trapping capacity in patients with Sjøgren's syndrome)

Massry, S. G., Preuss, H. G., Maher, J. F., AND Schreiner, G. E. (1967) Amer. J. Med., 42, 284 (Renal tubular acidosis after cadaver kidney homotransplantation: studies on mechanism)

Mirne, M. D. (1963) In 'Diseases of the Kidney', eds. M. D. Strauss and L. J. Welt, p. 786. Little, Brown, Boston

MORRIS, R. C., JR., AND FUdENBERG, H. H. (1967) Medicine, 46, 57 (Impaired renal acidification in patients with hypergammaglobulinaemia)

PITTS, R. F. (1974) In 'Physiology of the Kidney and Body Fluids', p. 210. Year Book Medical Publishers, Chicago

SCHIRMER, O. (1903) Cited in 'System of Ophthalmology' (1965), Vol. VIII, Part 1, p. 132. Ed. E. S. Duke. Kimpton, London

SheARN, M. A., AND Tu, W. H. (1965) Amer. J. Med., 39, 312 (Nephrogenic diabetes insipidus and other defects of renal tubular function in Sjøgren's syndrome)

- _ (1968) Ann. rheum. Dis., 27, 27 (Latent renal tubular acidosis in Sjøgren's syndrome)

SJøGREN, H. (1933) Acta ophthal. (Kbh.), 11, Suppl. 2, 1 (Zur kenntris der Kerato conjunctivitis Sicca)

Talal, N. (1966) Bull. rheum. Dis., 16, 404 (Sjøgren's syndrome)

-, AND Bunim, J. J. (1964) Amer. J. Med., 36, 529 (The development of malignant lymphoma in the course of Sjøgren's syndrome)

Wrong, O. M., AND Davies, H. E. F. (1959) Quart.J. Med., 28, 259 (The excretion of acid in renal disease) 